Research Article

Hussein Yousif Aziz*, Baydaa Hussain Maula, and Basim Jabbar Abbas

\title{
Evaluation of stabiliser material using a waste additive mixture
}

https://doi.org/10.1515/eng-2020-0034

Received Oct 29, 2019; accepted Mar 12, 2020

\begin{abstract}
To eliminate problems caused by gypsum soil in Iraq (due to gypsum salt under building foundations and projects), this study evaluates the effect of using the proposed stabiliser additives (vehicle waste oil and asphalt powder) to produce a composite enhancement material as a novel solution by examining the shear strength of the gypseous soil using the direct shear and constant head permeability tests. Three burned-oil weights were used (3\%, $5 \%$, and $7 \%$ by dry soil weight), which were mixed with a constant quantity of asphalt powder $(10 \%$ of the sample weight) to investigate the shear strength of the composite material. Several factors were considered in this study, including soaking time and moisture content.

The main findings reveal that composite material could improve the strength of the gypseous soil. The stabiliser reduces water leakage and percolation by forming an impermeable layer with a very fine texture, causing a significant reduction in the permeability coefficient, which improves the gypseous soil and reduces the collapse phenomenon.
\end{abstract}

Keywords: Asphalt powder, collapsed gypsum, shear strength, stabilization, impermeable layer; composite materials

\section{Introduction}

Collapsible soil or rock is considered a severe problem that faces civil engineers when constructing structures. Excessive settlement may suddenly occur due to water leakage into cracks in the construction during rainfall or the rise of the water table level.

\footnotetext{
${ }^{\star}$ Corresponding Author: Hussein Yousif Aziz: Al-Muthanna University, College of Engineering, Sammawa, Iraq, Email: husseinyousifaziz@mu.edu.iq

Baydaa Hussain Maula: Institute of Technology-Baghdad, Middle Technical University, Baghdad, Iraq

Basim Jabbar Abbas: Al-Muthanna University, College of Engineering, Sammawa, Iraq, Email: basim.gabar@mu.edu.iq
}

Many researchers have studied the collapsibility behaviour of gypseous soils, which is called the collapse potential. Arid and semi-arid areas contain gypseous soil as a result of storing the rainwater that is needed to wash the gypsum from the soil. It is present in the soil as hydrated calcium sulphate $\left(\mathrm{CaSO}_{4} \cdot 2 \mathrm{H}_{2} \mathrm{O}\right)$, which is crystalline, or as anhydrous calcium sulphate $\left(\mathrm{CaSO}_{4}\right)$, which is the noncrystalline form [1]. The gypsum percentage can be low or high in rocks and can reach up to $90 \%$. The specific gravity of gypsum is 2.3 [2], and it is a water-soluble salt [3]. Thus, to dissolve gypsum, the temperature and velocity of water flows need to be considered. One of the most complicated engineering problems that face civil engineers is the presence of gypsum in the soil [4] due to several factors, such as temperature, moisture content, and the presence of certain types of salt. Therefore, these factors should be considered and measured before any construction takes place. Gypsum soil has many problems that are challenging for the engineers responsible for projects based on this soil type. Many cases of collapse or cracking are recorded in buildings in different areas of Iraq with gypsum soils, for example, the defects in hotel Samarra due to gypsum exuding from the soil. In addition, the continuous leaching of gypsum from the soil caused the dam of Mosul to be vulnerable to collapse, prompting engineers to inject the dam floor with cement to fill the voids. Another case of collapse occurred in Habbaniyah, a tourist city, which suffered damage and defects due to the presence of gypsum soil [5]. Some researchers have turned to the method of waste recycling which can be considered as one of the measures of sustainable methods forimproving the properties of soil and concrete [6-8]. Many studies have assessed inexpensive functional materials to improve gypseous soil. Al-Zory [9] studied the treatment of the gypseous soil with lime, [10] and other researchers have used cement or bituminous materials [11], whereas Esho (2004) suggested emulsion asphalt [12]. In addition, both lime and emulsion asphalt were added in another study [13].

These investigations demonstrate that these techniques can facilitate controlling the effects of gypsum. Many studies have focused on increasing the strength, reducing the permeability, and improving the characteristics of the soil [14-18]. It is worth noting that research efforts to 
improve the soil were not limited to the practical side only, as there are several researches conducted numerically on improvement [19], this study was carried using finite element software (Plaxis) in studying the Engineering behavior of erodible soil-quarry dust composite at a proportion of $50 \%$ quarry dust and $10 \%$ cement.

In this work, new economical materials are introduced. These materials are impermeable and can hold structure loads.

The materials contain gypseous soil, which is treated with waste oil (WO). The behaviour of the WO and asphalt powder (AP) in the gypseous composite material is studied using the direct shear and permeability tests.

\section{Materials and Methods}

\subsection{Soil and Stabiliser}

The soil used in this study is a mixed sandy clay soil with a high percentage of gypsum at about $50 \%$, which behaves as gypseous soil with high permeability and collapsibility, requiring treatment with a stabiliser. The physical behaviour of gypseous soil is represented by classification tests on the soil using a series of laboratory tests that include particle-size distribution, Atterberg limits, relative density, and compaction characteristics. The results are given in Tables 1 to 4.

The proposed stabiliser consists of two materials: a WO (brownish-black petroleum fractions consisting

Table 1: Results of the sieve analysis of the untreated gypseous soil [ASTM D422-63, 2007]

\begin{tabular}{ccccc}
\hline Passing \% & Cum \% & \% Ret & Ret & Sieve. no \\
\hline 86.2 & 13.8 & 13.8 & 138 & 4.75 \\
76.9 & 23.1 & 9.3 & 93 & 2.36 \\
63.9 & 36.1 & 13 & 130 & 1.18 \\
55.6 & 44.4 & 8.3 & 83 & 0.6 \\
33.5 & 66.5 & 22.1 & 221 & 0.3 \\
12.4 & 87.6 & 21.1 & 211 & 0.15 \\
1.3 & 98.7 & 11.1 & 111 & 0.075 \\
\hline
\end{tabular}

Table 2: Results of the liquid limit test of the untreated gypseous soil [ASTM D4254-2000]

\begin{tabular}{ccc}
\hline Wc\% & No. blows & No. \\
\hline 12.5 & 60 & 1 \\
18.8 & 17 & 2 \\
20.3 & 10 & 3 \\
\hline
\end{tabular}

Table 3: Results of the plastic limit test of the untreated gypseous soil [ASTM D4254-2000]

\begin{tabular}{ll}
\hline & P.L $=11.1 \%$ \\
\hline 20 & Weight of wet sample(gm) \\
18 & Weight of dry sample $(\mathrm{gm})$
\end{tabular}

Table 4: Results of the compaction test of the untreated gypseous soil [ASTM D1557-00, 2007]

\begin{tabular}{cccccc}
\hline $\begin{array}{c}\text { Density } \\
(\mathrm{gm} / \mathrm{cm} 3)\end{array}$ & 1660 & 1679 & 1690 & 1654 & 1511 \\
$\mathrm{Wc} \%$ & 6.33 & 7.48 & 10.5 & 11.715 & 13.558 \\
\hline
\end{tabular}

mainly of the distilled residues from asphalt-type crude oils, with a relative density of about 0.95 [20-22]) and AP, which can be obtained from the waste of old asphalt pavement ground to a powder.

\subsection{Design of Soil - Stabiliser Material Preparation}

To prepare the tested specimens, the soil passing sieve No. 4 was oven-dried at a temperature of $105^{\circ}$. For the test, the prepared specimens were divided into two groups as shown in Figure 1. For the first group, to calculate the maximum dry unit weight or density and the optimum moisture content and dry density of the soil, the standard compaction test was used, resulting in $16.9 \mathrm{kN} / \mathrm{m}^{3}$, which was selected as a reference in the compaction process. Next, the prepared soil was placed into square moulds $(60 \times 60$ $\mathrm{mm} \times 20 \mathrm{~mm}$ ) to calculate the shear strength using the direct shear test. Finally, the rest of the specimen was tested for permeability at different immersion times $(3,10,30$,

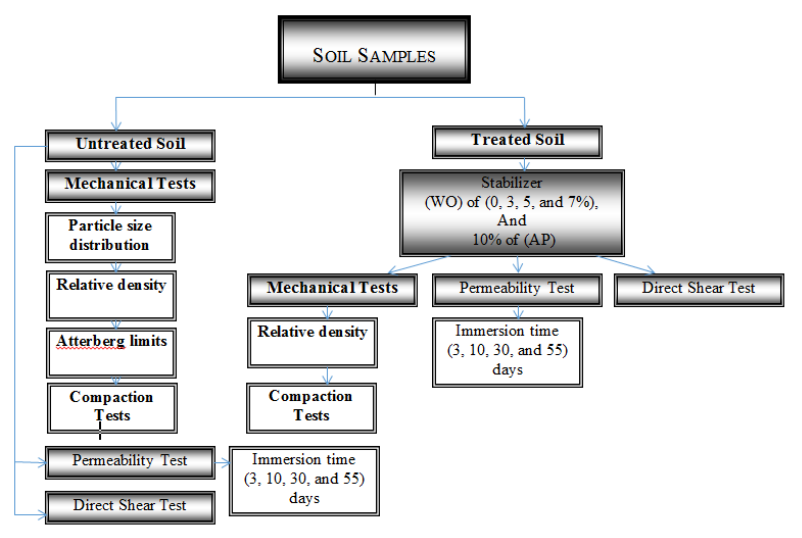

Figure 1: Flowchart of the research methodology 


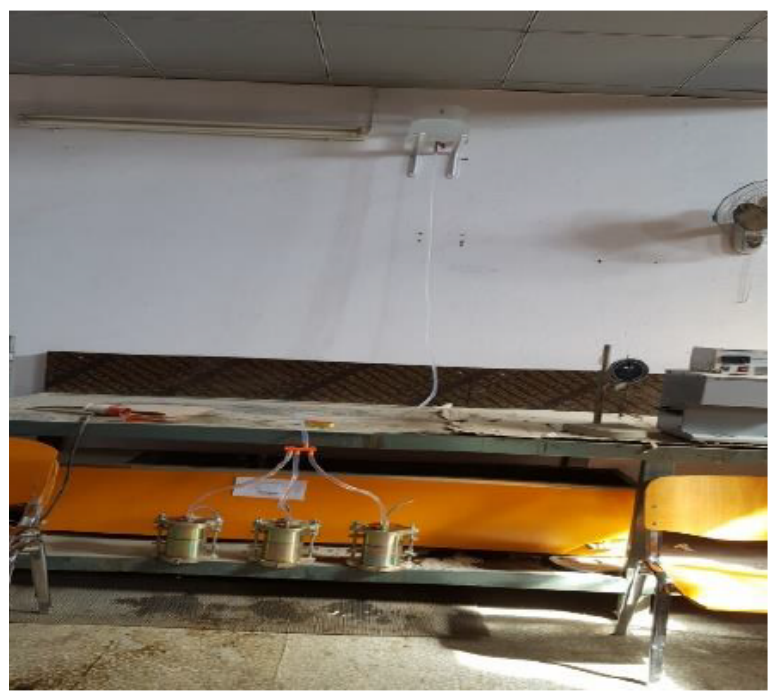

Figure 2: Model setup for the permeability and durability test

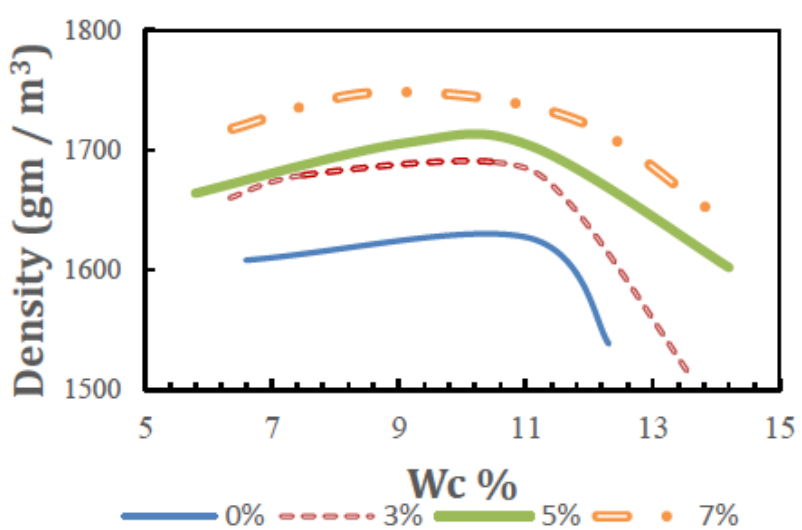

Figure 3: Effect of stabiliser percentage on moisture content and dry density curves

and 55 days), applying a water height of $2.0 \mathrm{~m}$. The permeability tests were measured daily and then weekly until the soil collapsed [ASTM D434], as shown in Figure 2.

The second group included the treated specimens prepared by compacting the gypseous soil with different WOs at $0 \%, 3 \%, 5 \%$, and $7 \%$ with $10 \% \mathrm{AP}$ at the corresponding optimum moisture content for different WO percentages.

The specimen was mixed with WOs at different weight ratios (i.e., $\mathrm{Wr}=(\mathrm{Wa} / \mathrm{WS}) \times 100 \%=0 \%, 3 \%, 5 \%, 7 \%$ ). First, the stabiliser and distilled water were added to the container and stirred to obtain an evenly viscous solution. Then, this solution was added to the prepared soil and mixed to obtain soil-stabiliser material.

The second group included the treated specimens prepared by compacting the gypseous soil with different WOs

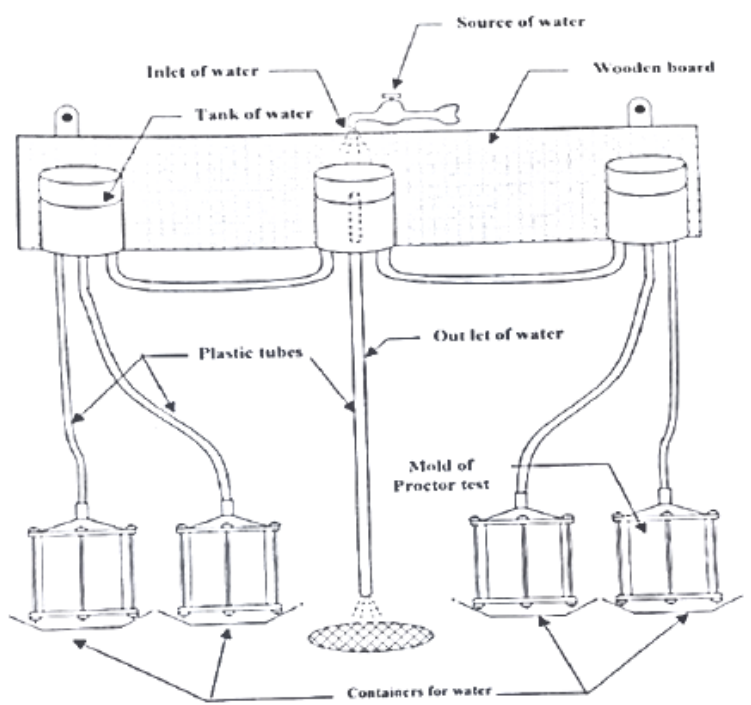

at $0 \%, 3 \%, 5 \%$, and $7 \%$ with $10 \% \mathrm{AP}$ at the corresponding optimum moisture content for different WO percentages.

The specimen was mixed with WOs at different weight ratios (i.e., $\mathrm{Wr}=(\mathrm{Wa} / \mathrm{WS}) \times 100 \%=0 \%, 3 \%, 5 \%, 7 \%$ ). First, the stabiliser and distilled water were added to the container and stirred to obtain an evenly viscous solution. Then, this solution was added to the prepared soil and mixed to obtain soil-stabiliser material. Next, the treated specimens were exposed to the same test that was applied to the untreated group.

\subsection{Laboratory Shear Test}

The shear strength behaviour of the soil-stabiliser material after curing was studied using the direct shear test.The shear stress-displacement curve is pictured separately under the normal stress $(\sigma)$ of 14,27 and $40 \mathrm{kPa}$ at a shear rated speed of $0.4 \mathrm{~mm} / \mathrm{min}$.

The model of the test was untrained to show the effect of consolidation in the soil within the process of loading over time [ASTM D3080]. The mixed materials were carefully transferred to the shear box in three layers with compaction to achieve the corresponding maximum unit weight. Three normal stresses of 14, 27 and $40 \mathrm{kPa}$ were used to consider the stress range in the field applications.

The shear strength parameters, including cohesion (c) and the internal friction angle $(\varphi)$, are calculated using Coulomb's law of shear strength, as shown in Formula (1):

$$
T=\sigma x \tan \phi+\mathrm{c}
$$



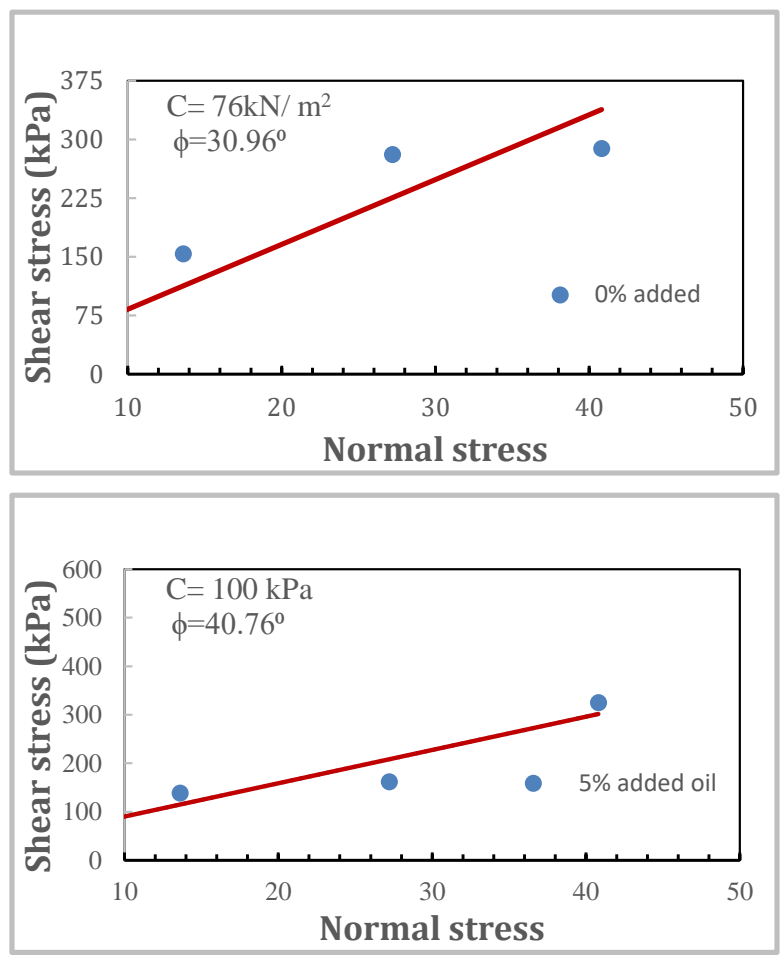

Figure 4: Shear stress versus normal stress values (failure envelope)

where $\tau$ is the shear strength of the soil equal to shear force to an area at $S / A$, c denotes the cohesion of the soil mass, $\varphi$ represents the angle of the shear resistance for the soil, and $\sigma$ is the normal stress equal to normal force to area soil mass at $N / A$.

\section{Results}

\subsection{Effect of Compaction}

Mixed gypseous soils with AP and different percentages of WO were used to study the effect of the proposed stabiliser on the compaction characteristics (i.e. maximising the optimum moisture content and dry density). The compaction test was conducted according to [12]. The maximum dry density was obtained according to the WO percentage, which is considered the corresponding water content. To prepare all tested samples, the standard proctor mould with a diameter of 4 in and a height of 4.6 in and a $5.5 \mathrm{lb}$ standard hammer were used, and the samples were compacted in three successive layers using 25 blows for each layer.

Figure 3 shows the dry density moisture content relationship curves of the soil-stabiliser material. From these relationships, the values of the maximum mixture dry den-
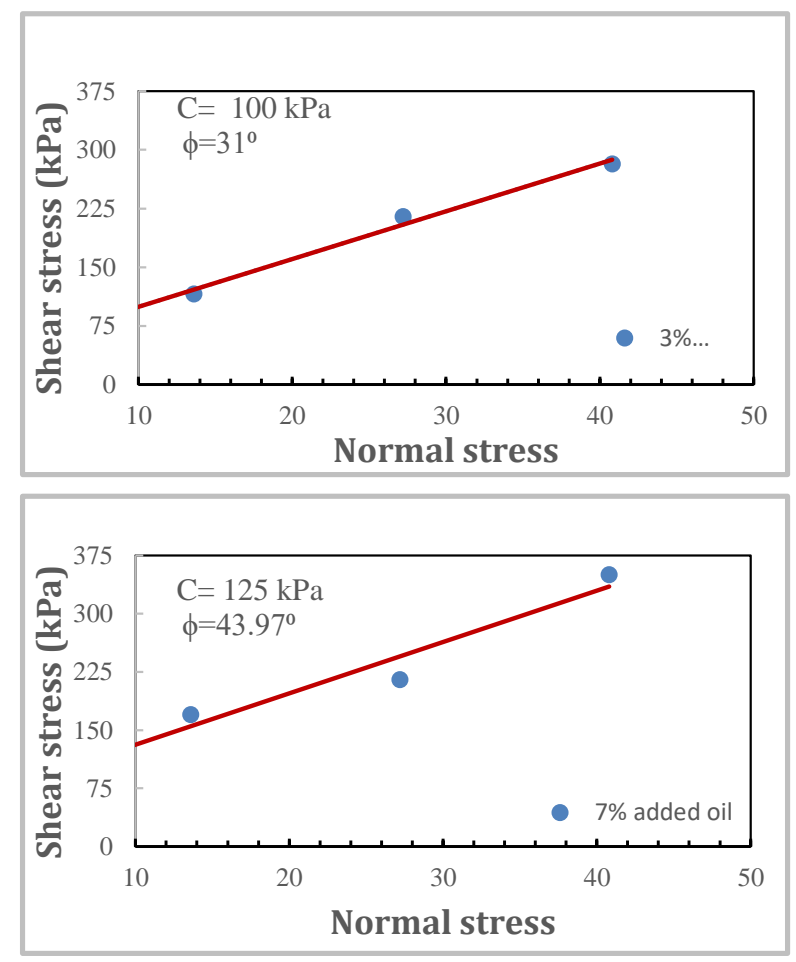

sity and optimum moisture content can be obtained. The compaction curve shapes for the treated soil are similar to that of the untreated sample. The maximum dry unit weight or density of the soil-stabiliser mixtures increases with an increase in the WO. The figure illustrates the considerable effect of the WO percentage on the moisture content value.

\subsection{Failure Mode Results}

All untreated and treated specimens were sheared alone first with the direct shear box to determine their frictional characteristics.

The two groups of soil specimens reached their ultimate shear strength in the untreated state under the normal stresses of 13, 27, and $40 \mathrm{kPa}$, as shown in Figure 4.

The figure demonstrates that the cohesion (c) and angle of shear resistance $(\varphi)$ increased with an increase in the stabiliser percentage. The untreated soil specimens clearly have a low cohesive value due to the small volume of soil particles passing from sieve No. 0.075.

The increase in cohesiveness is attributed to the stabiliser, which affords the soil the property of fine minerals and fills the voids of the sandy soil, making it more cohesive. In addition, the increment in the angle of friction $(\varphi)$ was very small for a stabiliser of $3 \%$ WO. From these test tri- 
als, the effective percentage of stabiliser that can be used with gypseous soil is $7 \%$.

\subsection{Peak Shear Strength}

The maximum shear strength is reported in Figure 5. The direct shear tests for the untreated soil and soil-stabiliser specimens were conducted under the same normal loading and testing protocol for the sake of comparison. To discuss the effects of adding stabiliser on the stressdeformation behaviour of the tested specimens, the results of the direct shear tests under $40 \mathrm{kPa}$ (as an example) are presented in Figure 5. The results show that a well-defined peak shear strength is not observed for the soil stabiliser. Generally, the yield shear stress is reached at a small horizontal displacement of less than $1.0 \mathrm{~mm}$.

It became constant after a displacement of $1.0 \mathrm{~mm}$. The percentages of $0 \%, 3 \%$ and $7 \%$ were used because the soils show more shear strength than the other case of $5 \%$ stabiliser.
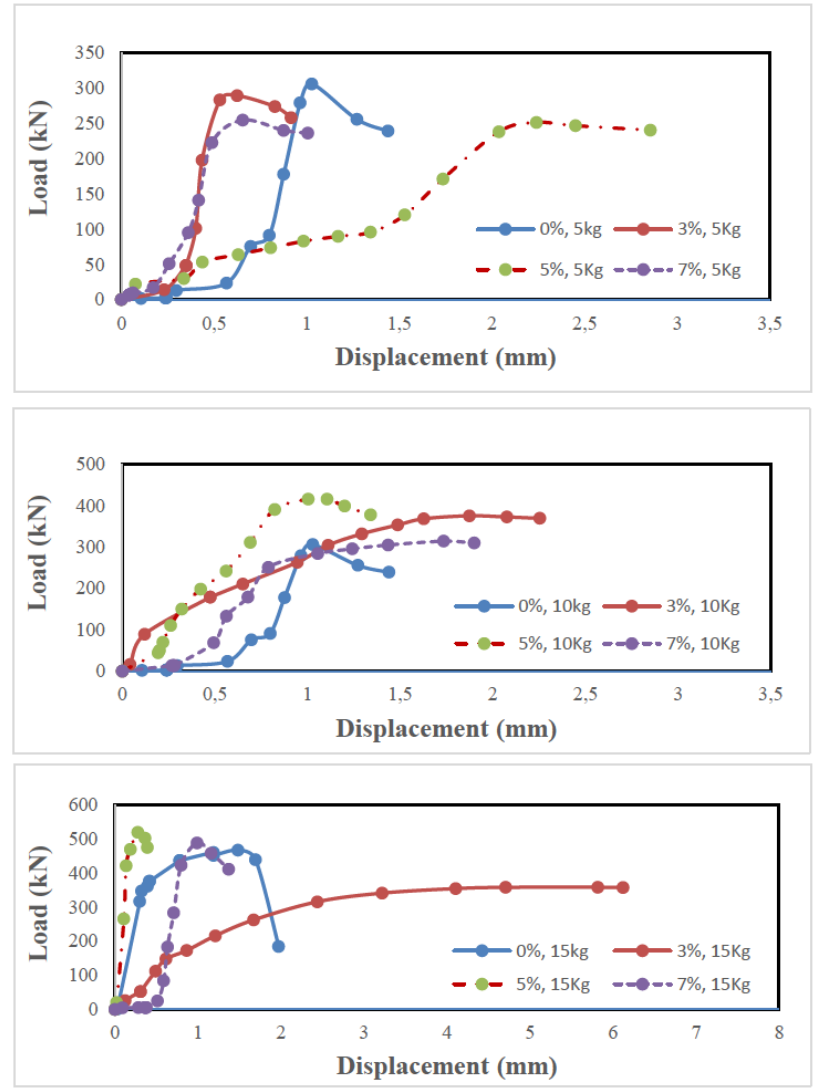

Figure 5: Horizontal deformation versus shear stress under $40 \mathrm{kPa}$ of normal loading
There is no effect on moisture content, which produces a higher dry density value, and it is not necessary to show a higher shear resistance than for the other specimens.

By calculating the shear strength, which depends on the angle of internal friction of the soil and the cohesion, whether the soil strength is increased or decreased with treatment can be estimated. Therefore, a foundation with the dimensions of $2.0 \times 2.0 \mathrm{~m}$ as single footing with a depth of $1.5 \mathrm{~m}$ was taken as an example to calculate the bearing capacity using the Terzagi method depending on the angle of internal friction and the cohesion.

The results were as follows:

- $\mathrm{Q}(0 \%)=9172.3 \mathrm{kN} / \mathrm{m}^{2}$

- $\mathrm{Q}(3 \%)=15390.5 \mathrm{kN} / \mathrm{m}^{2}$

- $\mathrm{Q}(5 \%)=19351.671 \mathrm{kN} / \mathrm{m}^{2}$

- $\mathrm{Q}(7 \%)=28131.8 \mathrm{kN} / \mathrm{m}^{2}$

From the above results, the bearing capacity increased by increasing the percentage of treatment despite that the cohesion values decreased. This might be attributed to the increase in the values of the angle of internal friction, which counteracts the lower cohesion values.

\subsection{Constant Head Permeability Test}

Figure 6 shows the relationship between the flow of water in a pipe for the constant head permeability test and the duration of time. From the figure, the head of water is reduced over time until reaching zero within 1.5 hours, which means that the soil has high permeability.

This sample will fail (collapse within 1 day after 3 days of applying a head of $1.35 \mathrm{~m}$. The results are shown in Figures 7 to 10 .

The effect of treatment with $3 \%, 5 \%$, and $7 \%$ of WO on permeability is shown in Figures 7 to 10.

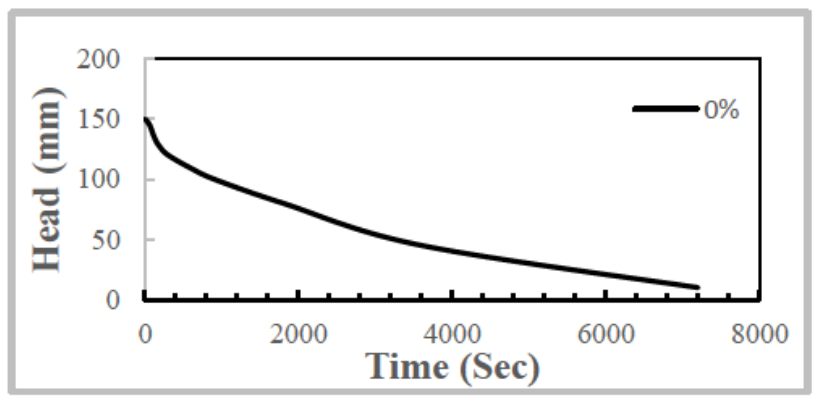

Figure 6: Relationship between falling water in a pipe for the constant head permeability test and the duration of time for untreated soil ( $0 \%)$ at 3 days of soaking 


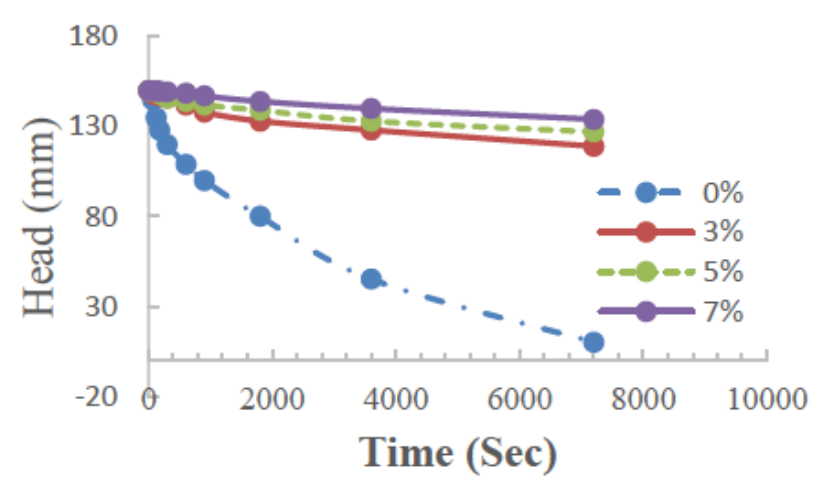

Figure 7: Relationship between falling water in a pipe for the constant head permeability test and the duration of time for untreated and $3 \%, 5 \%$, and $7 \%$ stabiliser-treated soil after 3 days of soaking

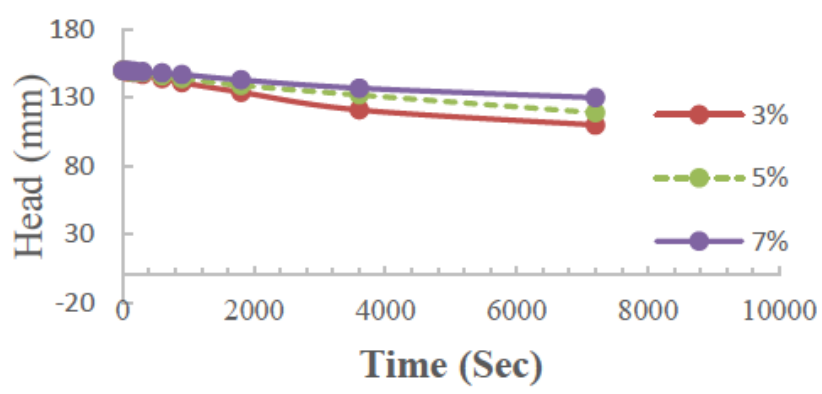

Figure 8: Relationship between falling water in a pipe for the constant head permeability test and the duration of time for untreated and $3 \%, 5 \%$, and $7 \%$ stabiliser-treated soil after 3 days of soaking

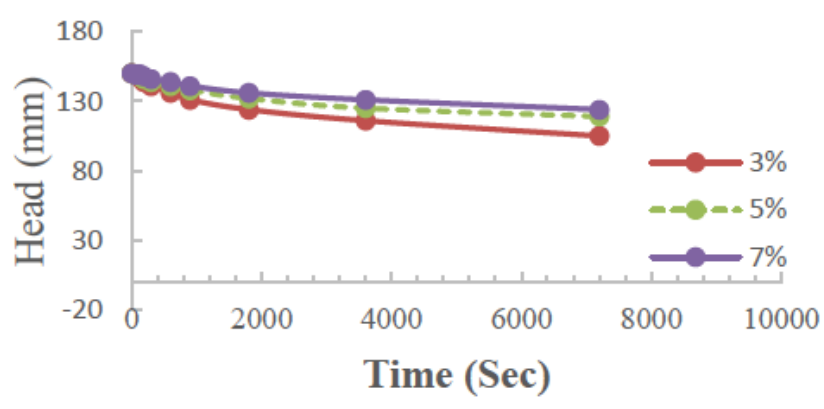

Figure 9: Relationship between falling water in a pipe for the constant head permeability test and the duration of time for $3 \%, 5 \%$, and $7 \%$ stabiliser-treated soil after 30 days of soaking

The values of permeability are represented with the coefficient of permeability ( $k$ ). The figures show that the coefficient of permeability is reduced over time with an increasing percentage of treatment. This leads to an increase in the density and reduces the voids between particles, which leads to reducing the permeability and reducing the effects of leaching and collapsibility. From the above results, the treatment with the proposed stabiliser is useful to modify the soil properties represented by the density and perme-

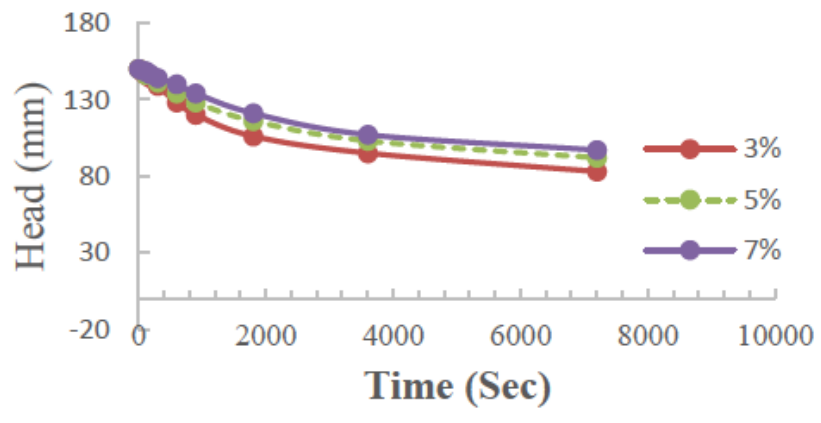

Figure 10: Relationship between falling water in a pipe for the constant head permeability test and the duration of time for $3 \%, 5 \%$, and $7 \%$ stabiliser-treated soil after 55 days of soaking

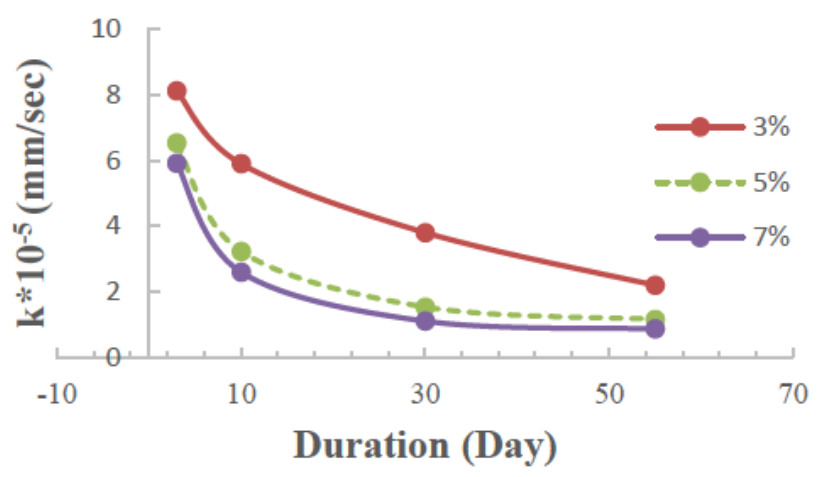

Figure 11: Comparison between $\left(\mathrm{k}^{\star} 10^{-5}\right)$ coefficients of permeability with $3 \%, 5 \%$, and $7 \%$ stabiliser applied to the soil

ability, which are the main problems in gypseous soils, as illustrated in Figure 11.

\section{Discussion}

By treating the gypseous soil with a stabiliser (i.e. 3\%, 5\%, and $7 \% \mathrm{WO}$ and $10 \% \mathrm{AP}$ ), the properties of the gypseous soil and its behaviours can be summarised as follows. For the treated soil, permeability and leaching decreased because the void ratio was reduced and caused lubrication between the soil particles, which reduced the voids and rearranged the particles.

The treatment of soil with a 5\% stabiliser increased the durability compared to untreated soil. The $7 \%$ stabiliser was beneficial for all periods of the tests and may still be durable for a long time in the structure. The aim of this study was achieved by enhancing the permeability of the stabilised soil because this is the most important factor for soil failure, and it was solved using material available in Iraq. The soil properties for gypsum soil particles were improved by coating with $\mathrm{WO}$ and AP, which prevented collapse by reducing the dissolution of the gypsum. The co- 
hesion was increased, and a suitable bearing capacity was maintained for carrying the loads.

To avoid the collapsibility of gypseous soil, a mixture of 3\% WO and AP was used for sandy soils to create a suitable solution. In addition, the bearing capacity value was maintained to handle structure loads. The use of AP and WO was successful in improving the properties of the gypseous soils and may be considered the proposed method to provide the fullest advantage to modify the soil, compared with previous studies. This method of treatment using WO mixed with AP is considered the first method to treat the lack of cohesion and to increase the shear strength and bearing capacity of the soil.

\section{References}

[1] Buringh P. Soils and conditions in Iraq. Baghdad, Iraq: Ministry of Agriculture; 1960.

[2] Blyth FG. A geology for engineers. 5th ed. London: Edward Arnold Ltd.; 1971.

[3] Barazanji AF. (1973). Gypsiferous soils of Iraq. PhD thesis, University of Ghent, Belgium

[4] Al-Saoudi NK. (2013). 'Challenging problems of gypseous soils in Iraq'. Proceedings of the 18th International Conference on Soil Mechanics and Geotechnical Engineering, Paris

[5] Al-Zory EA. (1993). The effect of leaching on lime stabilized gypseous soil. MSc thesis, Mosul University

[6] Hamdan RK, Sarsam SI. Impact of Rejuvenators Type on Physical Properties of Aged Asphalt Cement. Civil Engineering Journal. 2019;5(9):2058-69.

[7] Jajin MG, Hamedi GH. Examining the Effect of Dry Resin on Moisture Sensitivity of Asphaltic Mixtures. Civil Engineering Journal. 2018;4(7):1714-27.

[8] Gamil, Y., Bakar, I., \& Ahmed, K. (2017). Simulation and development of instrumental setup to be used for cement grouting of sand soil. Emerging Science Journal, 1(1), 16-27. https://doi.org/10.28991/esj-2017-01112.

[9] O’Flaherty CA. (1988). Highways: Volume 1 highway engineering. 3rd ed., Edward Arnold, London
[10] Al-Morshedy AD. (2001). The use of cut-back MC-30 for controlling the collapsibility of gypseous soils. MSc thesis, Building and Construction Department, University of Technology

[11] Al-Alawee AB. (2001). Treatment of Al-Therthar gypseous soil by emulsified asphalt using mold test. MSc thesis, Building and Construction Department University of Technology, Baghdad

[12] Esho BG. (2004). Stabilization of gypseous soils by lime and emulsified asphalt. MSc thesis, College of Engineering, University of Mosul

[13] Bushra S. 'Treatment of gypsum soil breakdown' [in Arabic]. J Eng (Stevenage). 2008;14(3):444-57.

[14] Liu, J. et al. (2018). 'An experimental study on the shear behaviors of polymer-sand composite materials after immersion'. Polymers 10.8: 924, https://doi.org/10.3390/polym10080924.

[15] Fattah MY, Al-Ani MM, Al-Lamy MT. 'Studying collapse potential of gypseous soil treated by grouting'. Soil Found. 2014;54(3):396404.

[16] Fattah MY, al-Musawi HH, Salman FA. 'Treatment of collapsibility of gypseous soils by dynamic compaction'. Geotech Geol Eng. 2012;30(6):1369-87.

[17] Al-Taie AJ, Al-Shakarchi YJ. 'Shear strength, collapsibility and compressibility characteristics of compacted Baiji Dune soils'. Journal of Engineering Science and Technology. 2017;12(3):76779.

[18] Aziz HY, Ma J. 'Gypseous soil improvement using fuel oil'. World Acad Sci Eng Technol. 2011;51:299-303.

[19] Emeka AE, Chukwuemeka AJ, Okwudili MB. Deformation behaviour of erodible soil stabilized with cement and quarry dust. Emerging Science Journal. 2018;2(6):383-7.

[20] Al-Otaibi FA. (2006). Assessment of the possibility of stabilising Sabkha soils using oil lake residue: Reuse of waste materials. Dissertation. Cardiff University

[21] Mahdi TA, Al-Otaibi F, Thomas HR. (2006). 'Sabkha soils mixed with oil lake residues: Reuse of a waste material'. 5th ICEG Environmental Geotechnics: Opportunities, Challenges and Responsibilities for Environmental Geotechnics: Proceedings of the ISSMGE 5th International Congress organized by the Geoenvironmental Research Centre, Cardiff University, Cardiff City Hall 26-30th June 2006. Thomas Telford Publishing

[22] Goodger EM. Hydrocarbon fuels. Volume 87. Macmillan International Higher Education; 1975. https://doi.org/10.1007/978-1349-02652-4. 